\title{
¿Historia o política? \\ Las lecturas peronistas del pasado correntino $(1946-1955)^{1}$ \\ María del Mar Solís Carnicer*
}

\section{Resumen:}

Es sabido que los poderes públicos apelan permanentemente al pasado, hacen uso de él, reescriben y reinterpretan la historia. En ese contexto, este artículo tiene por objeto indagar -una vez más- sobre la tensa y compleja relación entre historia y política. En particular, se focaliza en el análisis de los usos del pasado por parte del peronismo, movimiento político que irrumpe en la política argentina a mediados del siglo XX y que no fue ajeno a estas prácticas con las cuales buscó reinterpretar la historia nacional a fin de legitimar su posición. En Corrientes, una provincia que se había caracterizado por el predominio de una política de corte liberal-conservador, acompañado por interpretaciones históricas muy cercanas a esos partidos políticos tradicionales, los cuestionamientos al modelo liberal y el rescate de las tradiciones hispánicas y católicas fueron algunas de las herramientas a las que el peronismo apelará en esa operación historiográfica y política.

Palabras claves: Peronismo, política, usos del pasado, Corrientes, Argentina.

\begin{abstract}
:
It is known that authorities constantly appeal to the past, and make use of it, they rewrite and reinterpret history. This paper aims to further investigate the tense and complex relationship between history and politics. In particular, the analysis focuses on the uses of the past by the Peronism, a political movement that burst into the Argentinian policy in the mid twentieth century and was not immune to the practices that sought to reinterpret the national history in order to legitimize its position. In Corrientes, a province that had been characterized by the dominance of a liberal and

\footnotetext{
1 Una primera versión de este trabajo fue presentada en las XIII Jornadas Interescuelas Departamentos de Historia realizadas en la Universidad de Catamarca en agosto de 2011. Agradecemos los comentarios que en aquella oportunidad nos hiciera Liliana Brezzo así como las sugerencias y observaciones de María Gabriela Quiñonez, María Silvia Leoni y los demás colegas del Grupo de Historia de la Historiografía de la Facultad de Humanidades de la UNNE con los cuales venimos indagando sobre estos temas desde hace ya varios años. También fueron enriquecedores los comentarios de los evaluadores de la revista y las sugerencias que nos realizara Fernando Araujo Sa. Sus aportes fueron de gran valor para reformular nuestras preguntas y buscar nuevas respuestas.

* Universidad Nacional del Nordeste e Conicet / Argentina. E:mail. marimarsolis@yahoo.com.ar.
} 
conservative politics plus historical interpretations very close to these traditional political parties, the questions to the liberal model and the rescue of the Hispanic and Catholic traditions were some of the tools used by the Peronism in its historiographical and political operation.

Keywords: Peronism, politics, use of the past, Corrientes, Argentina

Una sociedad se aproxima a su pasado de diferentes maneras y por lo tanto, existen sobre él diversas reconstrucciones y representaciones, siendo las realizadas por los historiadores solo una de ellas. A su vez, esas interpretaciones dan lugar a la aparición de distintos pasados que disputan su legitimidad. Esos pasados -y sus resignificaciones- tienen también una función de legitimación de las prácticas políticas del presente y constituyen uno de los elementos claves en la construcción de identidades y por ello, se convierten en uno de los tantos espacios de disputa política. Los poderes públicos apelan permanentemente al pasado, hacen uso de él, reescriben y reinterpretan la historia, son generadores de memoria o de olvido institucionalizado.

El peronismo, como movimiento que irrumpe en la política argentina a mediados del siglo XX, no fue ajeno a estas prácticas y también hizo uso del pasado y apeló a él. Desde el poder buscó reinterpretar la historia nacional a fin de legitimar su posición a través de la construcción de una tradición particular que lo identificara y al mismo tiempo, lo diferenciara de las otras fuerzas políticas precedentes. En Corrientes, una provincia que se había caracterizado por el predominio de una política de corte liberalconservador $^{2}$ acompañada por interpretaciones históricas muy cercanas a esos partidos políticos tradicionales, los cuestionamientos al modelo liberal y el rescate de las tradiciones hispánicas y católicas fueron algunas de las herramientas a las que el peronismo apelará en esa operación histórica y política.

\footnotetext{
2 A diferencia de lo que ocurrió en otros países de América Latina en los que a fines del siglo XIX se plantearon fuertes enfrentamientos entre liberales y conservadores, en Argentina el conflicto inicial entre federales y unitarios y la polémica en torno al centralismo permeó el debate político, produciendo alineamientos y alianzas difíciles de reproducir en otros contextos. Es así que el régimen que se impone a partir de 1880 sea caracterizado como liberal-conservador puesto que propuso leyes e impulsó obras que significaban la concreción de los ideales del liberalismo pero al mismo tiempo creó un sistema político restrictivo en el que sectores amplios de la población tenían cerrados los canales de participación. La política correntina mantuvo estas características hasta mediados del siglo XX. Sobre los rasgos del denominado conservadurismo- liberal puede verse CORNBLIT, 1975; BOTANA, 1998 y MALAMUD, 1996-1997.
} 
Los "usos del pasado" o las "políticas de la memoria" 3 constituyen, en la actualidad, unas de las áreas de mayor crecimiento en la investigación y en el debate historiográfico. Partiendo de este enfoque, en este trabajo se busca reconstruir a las políticas de la memoria llevadas a cabo por el peronismo correntino con el objeto de dotar al naciente movimiento, de una identidad y una tradición que se enlazara con la historia misma de la provincia, liberada de los modelos culturales impuestos por el liberalismo.

Apoyándonos en la información que nos ofrecen los discursos de los principales dirigentes, los debates parlamentarios, la prensa y las publicaciones históricas y conmemorativas, nos propusimos reconstruir ese proceso, identificando los mecanismos utilizados, los actores intervinientes, las nuevas interpretaciones y los silencios sobre las figuras y hechos históricos provinciales y las conmemoraciones $\mathrm{u}$ homenajes celebrados. A partir de dicho análisis buscamos evaluar el impacto de esa operación y de las nuevas lecturas del pasado provincial que de ella resultaron, en la configuración ideológica del peronismo provincial y en los modos de historización de la sociedad correntina.

\section{Historia y política en Corrientes antes del peronismo.}

Desde fines del siglo XIX y hasta 1946, la provincia de Corrientes había sido gobernada en forma ininterrumpida por alguno de sus dos partidos provinciales tradicionales: el autonomista o el liberal. Ambos, surgidos en la segunda mitad del siglo XIX, respondieron inicialmente a los rasgos de los denominados partidos de notables, característicos de esos años. Hacia 1912 -y luego de la aparición del radicalismo en la arena política nacional y provincial- pasarán a identificarse con el conservadurismo ${ }^{4}$. A pesar de las diferencias que existían entre ellos, ambos (liberales y autonomistas)

\footnotetext{
3 El término "uso público de la historia" fue acuñado por Jurgen Habermas durante la controversia de los historiadores alemanes a mediados de la década del 80, pero su desarrollo en el campo de la historiografía se debe fundamentalmente a la obra del historiador italiano Nicola Gallerano. Uno de los principales aportes de este nuevo dominio de investigación consiste en su capacidad para ofrecer una visión más compleja de los modos en que circulan el conocimiento y la memoria históricos. (PASAMAR ALZURIA, 2003, pp. 221-248).

4 El partido radical que surge como oposición al partido gobernante a nivel nacional a fines del siglo XIX fue el primer partido de masas de la Argentina, se caracterizó por su carácter movimientista y por la defensa de la constitución nacional y del sufragio libre. Hipólito Yrigoyen, su líder, llegó a la presidencia en dos períodos (1916- 1922 y 1928-1930) dentro de la denominada etapa radical. Su segundo mandato fue interrumpido con el primer golpe militar a un gobierno democrático el 6 de septiembre de 1930. Los radicales, para diferenciarse de sus opositores empezaron a denominarlos conservadores, calificativo que fue asumido por sus adversarios como propio.
} 
respondían a una ideología de tipo liberal - conservador y habían construido un diseño institucional favorable a sus intereses.

La irrupción del peronismo hacia 1946 afectó profundamente a la política de la provincia, aunque estas transformaciones se dieron allí de manera diferenciada con respecto a lo ocurrido en las demás. El peronismo no consiguió llegar al gobierno provincial en esa elección, pero tampoco pudieron hacerlo los partidos provinciales que decidieron, entonces -con el propósito de impedir el triunfo peronista- apoyar al radicalismo. Por primera vez en la historia política de Corrientes ninguno de sus dos partidos tradicionales consiguió llegar al gobierno y de ese modo -y al mismo tiempo-, Corrientes se convertía en la única provincia argentina con un gobierno de signo político distinto al nacional. Solo una intervención federal -que llegará en 1947permitirá abrir el camino para el triunfo electoral del peronismo provincial en 1948. Juan Filomeno Velazco, un militar nacionalista, fue quien ocupó el cargo de interventor, primero (1947-1948) y de gobernador, después (1949-1952).

En paralelo a este proceso político, la interpretación de la historia provincial también estuvo dominada por una visión liberal. Los principales historiadores correntinos de la primera mitad del siglo XX fueron, a su vez, destacados políticos y ejercieron diversos cargos en la política provincial y nacional. Entre ellos deben mencionarse especialmente a Manuel Florencio Mantilla (1853- 1909) y Hernán Félix Gómez (1888- 1945) que fueron los que construyeron las interpretaciones más generales de la historia provincial que lograrán cristalizarse ${ }^{5}$. Aún desde contextos políticos diferentes (Mantilla era liberal y Gómez autonomista) trabajaron acordes con la historiografía liberal de Buenos Aires en la valoración de la línea Mayo-Caseros (LEONI, 2003) ${ }^{6}$. Las únicas diferencias de los historiadores correntinos con aquélla se

\footnotetext{
5 Además de los dos autores mencionados también merecen recordarse a Manuel Vicente Figuerero (1864-1938), Valerio Bonastre (1881-1949), Francisco Manzi (1883-1954), Esteban Bajac (1874-1947), Juan Esteban Guastavino (1868-1947) y Ángel Acuña (...?-1957), que hicieron que la actividad historiográfica fuera prolífica en la primera mitad del siglo XX. En la década de 1940 comienza la producción de dos historiadores que marcarían con su labor la segunda mitad del siglo: Federico Palma (1912-1985) y Wenceslao N. Domínguez (1898-1984).

6 La historiografía liberal planteó una línea de continuidad entre la revolución de mayo de 1810 que permitió la emancipación de España y abrió el camino a la independencia y el proceso de organización nacional. Éste culminó con la sanción de la Constitución Nacional en 1853, un año después de la batalla de Caseros (1852) en la fue derrotado Juan Manuel de Rosas, gobernador de Buenos Aires con amplios poderes que había dominado la política local y que no había permitido la organización nacional durante el largo período de su predominio (1829-1852). Esta interpretación de la historia argentina fue planteada por los padres fundadores de su historiografía, Bartolomé Mitre y Vicente Fidel López, a fines del siglo XIX y fue continuada posteriormente por los historiadores de la denominada Nueva Escuela Histórica. Esta vertiente historiográfica plantea una valorización peyorativa de la etapa colonial y exalta el proceso revolucionario.
} 
manifestaron a la hora de evaluar el papel jugado por Corrientes en dicho proceso, al otorgarle a la provincia centralidad en la defensa de la libertad, el federalismo y la organización nacional. En coincidencia con la historiografía liberal, defendieron las ideas democráticas y juzgaron a Juan Manuel de Rosas como un tirano que cercenó la autonomía provincial e impidió la definitiva organización del país (LEONI, 2004, pp. $15-41)$.

El tema de la "cruzada libertadora" contra la tiranía rosista (las campañas militares emprendidas por la provincia de Corrientes entre 1839 y 1852) fue central en su historiografía, en la que se engrandecía a la figuras de Genaro Berón de Astrada denominado "el mártir de Pago Largo" y se demonizaba a Rosas ${ }^{7}$. Esta visión de la historiografía de Corrientes fue acompañada por el estado provincial que, especialmente a partir de los años veinte prestó su atención preferente a la difusión de la historia y la cultura correntinas. La irrupción del revisionismo en la década de $1930^{8}$-una corriente historiográfica que reivindicaba la figura de Rosas con una actitud de clara ruptura de la tradición liberal-, generó una importante reacción de la elite dirigente correntina y movilizó a los historiadores y al gobierno ante la proximidad del centenario de Pago Largo en 1939. Las obras publicadas por los historiadores correntinos durante los años '30 se dedicaron con preferencia al estudio de la lucha contra Rosas, incluyendo argumentos que contrariaban las primeras manifestaciones del revisionismo (QUIÑNONEZ, 2000, pp. 19- 52).

Esta verdadera operación historiográfica llevada adelante por los historiadores y acompañada y difundida por el estado, se fijó profundamente en la conciencia histórica provincial. Un solo historiador correntino se animó a discutir esa visión cristalizada de la cruzada libertadora, fue Justo Díaz de Vivar (1889- 1944), que en algunos artículos

\footnotetext{
7 La historiografía correntina denomina "Cruzada Libertadora" a las cuatro batallas llevadas a cabo por ejércitos correntinos contra el gobernador de Buenos Aires, Juan Manuel de Rosas. Ellas fueron las de Pago Largo (1839), Caa Guazú (1841), Arroyo Grande (1842) y Vences (1847). En esa reconstrucción historiográfica, se reivindicaba las Batallas de Pago Largo -a pesar de haber significado una terrible derrota para el ejército correntino-, el triunfo de Caá Guazú con un ejército al mando del General Paz, y dos nuevas derrotas en Arroyo Grande y Vences, porque más allá del resultado de las mismas representaban la lucha de Corrientes por la organización nacional y contra la tiranía. Por otra parte, Genaro Berón de Astrada, gobernador de Corrientes que murió en el campo de batalla de Pago Largo se convirtió en una figura central de ese proceso llamándolo "el mártir de Pago Largo".

8 Se denomina revisionista a la corriente historiográfica surgida en la Argentina hacia la década de 1930, integrada por intelectuales nacionalistas de derecha, antimarxistas, antiliberales y antiimperialistas que se proponían escribir una historia opuesta a la visión liberal y hegemónica que ellos calificaban como falsificada. En ese proceso buscaron reivindicar a aquéllos héroes olvidados por esa historiografía como Juan Manuel de Rosas. Por ese motivo es que también se conoce a este movimiento como revisionismo rosista (DEVOTO y PAGANO, 2009, pp. 201- 285).
} 
publicados en la revista del Instituto Juan Manuel de Rosas y en su libro Las luchas por el federalismo (1936), pretendió reivindicar la figura de Rosas siguiendo una línea interpretativa totalmente novedosa para la historiografía de Corrientes (QUIÑONEZ, 2004, pp. 472- 479). Sin embargo, su obra fue casi ignorada por sus contemporáneos.

Más allá de que entre los historiadores correntinos existió una clara preferencia por el estudio del siglo XIX, la historia colonial también fue objeto de investigaciones y polémicas. Hubo quienes manifestaron una posición muy crítica hacia la conquista española y al papel de las órdenes religiosas acorde con las ideas liberales y anticlericales del positivismo de fines del siglo XIX (Mantilla y Figuerero) mientras que otros, adoptaron una posición más moderada o favorable hacia los conquistadores (Gómez). Sin embargo, y más allá de los diversos matices, todos ellos consideraron a las Misiones Jesuíticas como una intromisión en el territorio provincial (MAEDER, 2004, pp. 171-188).

Uno de los temas en torno a los cuales se realizaron los mayores debates fue el relacionado con el suceso del "milagro de la cruz". Un hecho sobrenatural que -según la tradición- ocurrió en tiempos de la fundación de la ciudad y que derivó en la festividad cívico- religiosa más importante de Corrientes. Más allá de las diversas versiones que existen sobre el suceso, la tradición asegura que habiéndose instalado una cruz de madera en el fuerte levantado por los primeros pobladores de la ciudad, indígenas de la zona quisieron quemarla pero ésta no se consumió.

Mantilla en su Crónica Histórica de Corrientes (1928), negó la existencia del hecho milagroso y se manifestó muy crítico hacia los españoles y la conquista (MANTILLA, 1972, pp. 325-327). Igual posición adoptó Manuel Vicente Figuerero, mientras que Hernán Gómez en La fundación de Corrientes y la Cruz de los Milagros (una publicación póstuma salida a la luz en 1973), a partir de la información que pudo obtener de las Actas capitulares, llegó a una visión más moderada estableciendo que con respecto al milagro no importaba si éste había o no ocurrido sino la percepción que la sociedad había tenido sobre el mismo y la permanencia de la tradición que lo recordaba.

En momentos en que el peronismo accede al gobierno nacional no existía en Corrientes una institución que nucleara a sus historiadores. En 1937 el gobierno de la provincia había fundado una Junta de Estudios Históricos presidida por Justo Díaz de Vivar, e integrada por Juan Ramón Mantilla, Hernán Félix Gómez, Pedro Díaz Colodrero y Manuel Vicente Figuerero pero dicha institución desapareció muy pronto, 
sin llegar a cumplir su cometido, con la temprana muerte de Hernán Gómez, su último presidente, en 1945. Además, las muertes sucesivas de Figuerero (1938), Díaz de Vivar (1944) Valerio Bonastre (1949), Esteban Bajac (1947) también afectaron el desenvolvimiento de las actividades historiográficas en Corrientes en esos años. En 1940 Wenceslao Néstor Domínguez (1898- 1984) fundó en Buenos Aires -junto a Ángel Acuña (..?- 1957)- el Instituto Correntino de la Historia. Con dicha institución se intentó nuclear a algunas de las figuras representativas del quehacer historiográfico local, -todos ellos representantes de la corriente liberal predominante en la historiografía correntina hasta ese momento-. Pero la institución fue perdiendo importancia rápidamente debido al carácter marginal en el que se encontró a partir de la revolución de 1943. Resulta muy esclarecedor sobre el clima político e ideológico de la época, un breve aviso publicado en la prensa a fines de 1945 en el que se menciona que el Instituto había decidido cerrar abruptamente sus actividades académicas por ese año sin realizar -como lo hacía desde su creación- la conmemoración correspondiente al aniversario de la batalla de Caá Guazú ${ }^{9}$. Posteriormente, no realizará otras actividades o al menos, si existieron, no fueron comentadas por la prensa local.

Ninguna de estas instituciones logró convertirse en un verdadero punto de convergencia de los historiadores o en un foco de irradiación de los estudios históricos provinciales. Ante el fracaso de los distintos esfuerzos por crear ámbitos institucionales, la actividad siguió siendo una empresa de tipo individual, con contactos eventuales entre sus cultores, enfrentados muchas veces por ocupar los espacios oficiales y acceder a los recursos proporcionados por el estado (LEONI, 2004, p. 21).

\section{Peronismo, Hispanismo y catolicismo. El discurso de la Argentinidad}

Más allá de las profundas transformaciones que implicó la irrupción del peronismo en la política argentina, éste también se nutrió de las tradiciones políticas e ideológicas que lo precedieron. El nacionalismo constituyó una de estas vertientes, que tuvo especial incidencia en los años de formación del nuevo movimiento ${ }^{10}$. A través del

\footnotetext{
9 La Comisión Directiva del Instituto estaba presidida por Wenceslao Domínguez, Ángel Acuña era su vicepresidente. Secretario: Hernando Figuerero, Tesorero: Miguel Gelavert, Miembros titulares: Valerio Bonastre, Cnel. Pedro Grosso Soto, y José María Ruda. Wenceslao Domínguez (h) oficiaba de secretario adjunto. La Mañana. Corrientes, 19 de diciembre de 1945, p. 3.

10 Resultan de interés mencionar aquí los trabajos de Macor (2003) y Tcach (2006) que abordaron estas cuestiones para los casos de las provincias de Santa Fe y Córdoba respectivamente. En ambas provincias el nacionalismo, el hispanismo católico y un profundo antiliberalismo ocuparon también lugares centrales en el discurso y en el universo ideológico del primer peronismo.
} 
nacionalismo, el primer peronismo no solo incorporó simpatizantes y líderes sino que, al mismo tiempo, contribuyó en la construcción de un discurso político e ideológico alternativo al liberalismo que incluía una nueva representación del pasado y la inauguración de nuevos "itinerarios de memoria". Los cuestionamientos al modelo liberal, la defensa del hispanismo y del catolicismo de carácter integrista y el rescate de tradiciones históricas alternativas fueron, entre otros, los aportes que el nacionalismo hizo al peronismo que se plasmaron en medidas de gobierno tendientes a darles un carácter oficial.

Al presentarse como un movimiento fundacional, el peronismo buscó conformar una nueva conciencia nacional. En su estrategia cultural intentó integrar la herencia hispánica y católica con la cultura Argentina propia como componentes centrales de esta nueva conciencia (REIN, 1991) ${ }^{11}$. En paralelo, la Iglesia Católica irá tomando cada vez mayor injerencia en los asuntos públicos, lo que se refleja tanto en un cúmulo importante de medidas como en las permanentes referencias discursivas. Para internalizar la identidad católica fue fundamental la elaboración de una historia que, coincidente con la legitimidad postulada, enraizaba el pasado con el hispanismo católico. El peronismo según la interpretación que ellos mismos hacían del movimiento venía a

[...] reverdecer [el] viejo espíritu de la hispanidad, [...] la semilla de la gloria que derramaron en los campos de América las legiones de Isabel la católica [...]. (Convencional Luis Monferrer. Convención Constituyente 1949. 5 de mayo de 1949, pp. 24-25).

El mito de la nación católica se irá cristalizando rápidamente, un claro ejemplo de ello lo constituye la sanción de la ley que estableció la obligatoriedad de la enseñanza religiosa en las escuelas, medida que por decreto ya se había dispuesto en 1943 y que se convirtió en ley en 1947 (PUIGGROS, 2006, p. 328). El debate de este proyecto en el Congreso de la Nación, que tuvo como principal orador y protagonista al diputado correntino Joaquín Díaz de Vivar (hijo de Justo Díaz de Vivar, el único historiador revisionista que tuvo Corrientes), giró en torno a la identificación entre civilización, hispanidad y catolicidad como raíces de la nacionalidad argentina. La idea

11 Resulta interesante señalar aquí el rescate que el peronismo también hizo del folclore nacional a través de la adopción de diversas medidas como la obligatoriedad de difundir la música tradicional a través de la radio. No se observa una contradicción en esta cuestión con respecto al rescate de la tradición hispanista y católica ni tampoco significó un campo de disputa o conflicto al interior del peronismo correntino pues ambas perspectivas convivían y se complementaban. Sobre el peso de la tradición criolla en el imaginario peronista vehiculizado a través del folclore puede consultarse CHAMOSA, 2010. 
de la religión como esencia de la nación y la de la secularización y el laicismo como causa de la decadencia y de la desintegración social, la noción de la enseñanza católica como auténtica tradición argentina y como opción frente al peligro del comunismo; en definitiva la identificación entre la Iglesia, el Estado y el peronismo serán parte de los argumentos a los que se apeló en dicha discusión (BIANCHI, 2001, pp. 319-326). Estas ideas se reforzarán después en cada una de las provincias. En Corrientes, la misma Constitución provincial -reformada en 1949- estableció esta obligatoriedad por considerar que "el dogma católico apostólico romano, constituye la columna vertebral de nuestra civilización” y por ese motivo la educación debía estar conforme a él.

En la Constitución provincial, además, se reformó la fórmula de Juramento del gobernador, estableciendo que la misma debía hacerse por Dios y por la patria argumentando que eso debía ser así porque en la provincia de Corrientes "todos" profesaban la religión católica, porque era la religión de "toda" la república y porque era la que guiaba en "todos y cada uno de los principios" a los gobernantes nacionales y provinciales. Asimismo, la nueva Constitución estableció la obligatoriedad de que el gobernador profesara la religión católica, cláusula que no existía en las anteriores Constituciones de la provincia desde $1889^{12}$.

Son incontables las ocasiones en las que en los más diversos debates parlamentarios o en escritos periodísticos se realizaron paralelismos entre personajes bíblicos y los líderes peronistas o las veces que se utilizó un lenguaje religioso para caracterizar al peronismo. Esta identificación entre la religión católica, la argentinidad y el peronismo llevó en ocasiones a comparar a Jesús con Perón, Evita y los líderes del peronismo provincial como Juan Filomeno Velazco y a la Constitución equipararla con el catecismo máximo. Así lo señaló el presidente de la Convención Constituyente de 1949 al cerrar las sesiones ordinarias:

[...] con la amplitud de nuestros conceptos revolucionarios, en bien de la Patria y de la familia, sancionamos el Catecismo máximo de nuestras instituciones y que en él ciframos nuestras esperanzas ciudadanas, para que la verdadera justicia social, de raíz cristiana, cuyo excelso intérprete fuera el mártir del Gólgota y sus ejecutores indiscutidos son Perón, Evita y Velazco. (Corrientes. Convención Constituyente. Sesión ordinaria del 30 de mayo de 1949).

Esta unión entre el peronismo correntino y la religión católica se dio en todos los ámbitos, disponiéndose, por ejemplo, en noviembre de 1947, que todos los centros

12 Corrientes. Convención Constituyente. Sesión ordinaria del 30 de mayo de 1949, p. 176. 
peronistas debían llevar la imagen de la Virgen de Itatí y que al acto de entronización realizado en cada uno de ellos, -de carácter protocolar- debían asistir representantes del gobierno y de la Iglesia. Estos actos fueron muy cuestionados por la oposición que denunció permanentemente la apropiación que hacían los peronistas de los símbolos católicos y la confusión que generaban en la población al identificar el partido peronista con la Iglesia y con los símbolos de la fe más preciados de Corrientes ${ }^{13}$.

En este proceso de resignificación del pasado y de los símbolos religiosos en función del presente, la revolución del 4 de junio de $1943^{14}$, -considerada como la que dio origen al movimiento y por lo tanto la que vino a dar nueva vida a la Argentina-, había permitido reencontrar el pasado histórico nacional que estaba señalado por la cruz de Cristo y la bandera nacional. Se daba, entonces, una verdadera identificación entre el cristianismo y el peronismo:

Cómo no sentirnos satisfechos los peronistas de la hora presente cuando tenemos también aquel máximo derrotero que está fijado por la Cruz de Cristo? Es el mismo Cristo del Gólgota, el Cristo que ha dicho con su palabra, los verdaderos preceptos de la Justicia Social que hoy están enarbolados por Perón. [...] (Corrientes. Convención Constituyente. Sesión ordinaria del 30 de mayo de 1949, pp. 205-206).

Por otra parte, la declaración del 4 de junio como Día de la Argentinidad fue otro hecho más que confirmaba el planteo que se buscaba imponer. En 1947, en la conmemoración de un nuevo aniversario de dicha revolución, para entonces convertido en una fecha incorporada al calendario de festividades patrias, una nota editorial del Diario del Foro (identificado plenamente con el peronismo) titulaba: " 4 de junio: día de la Argentinidad" estableciendo con claridad la interpretación que el peronismo hacía de dicha celebración en la que se sentaban las bases del nuevo movimiento de tipo restaurador para la sociedad argentina en la que se entrelazaban las tradiciones nacionalistas y católicas. Se realizaba un paralelismo entre la revolución de mayo y la del 4 de junio en la que los militares pasaban a ser émulos de Jesús, cumpliendo no solo con un mandato cívico sino también evangélico ${ }^{15}$.

Esta reivindicación de las raíces católicas e hispánicas de la identidad argentina los llevará también a rescatar a ciertas figuras del pasado representativas de esta

13 La Mañana. Corrientes, 14 de diciembre de 1947, p. 3.

14 El 4 de junio de 1943 se produjo el golpe militar que derrocó al gobierno conservador de Ramón Castillo, durante el gobierno que le sucedió a dicho movimiento se gestó la figura política de Juan Domingo Perón.

15 El Diario del Foro. Corrientes, 4 de junio de 1947, p. 1. 
interpretación. Así por ejemplo, además de destacar el espíritu religioso de los principales héroes patrios -como San Martín y Belgrano-, se rescata el aporte de los clérigos en el proceso de la independencia, un hecho absolutamente novedoso en el discurso político e histórico de Corrientes ${ }^{16}$.

La restauración de los valores hispánicos y católicos fue señalada permanentemente como una de las principales acciones que el peronismo realizó en el ámbito de la cultura y la educación. Así lo reflejan las palabras pronunciadas con motivo de tratarse en la Legislatura provincial el proyecto de ley de creación de la Dirección provincial de Cultura en 1952. Allí, el diputado peronista César Espíndola Moreyra destacaba nuevamente la necesidad de retomar las raíces de la hispanidad como parte esencial de la identidad y la cultura argentina:

[...] hoy se ha retomado el hilo de aquella cultura casi olvidada, de esa cultura hispánica, de esa cultura de la cual podemos enorgullecernos nosotros porque España, [...] desde Carlos V hasta Felipe III, ha marcado rumbos a la humanidad en cuanto al florecimiento del pensamiento humano, en todas las manifestaciones del saber humano, así en las ciencias, como en las artes, como en la literatura (César Espíndola Moreyra. Corrientes. Cámara de Diputados. Diario de Sesiones. 17 de septiembre de 1952, p. 530).

Como corolario de esta identificación entre Iglesia y peronismo, en julio de 1951, por una iniciativa del obispo Mons. Francisco Vicentín y con el apoyo del gobierno provincial y nacional, se llevó a cabo en Corrientes el Primer Congreso Nacional de enseñanza religiosa en el que participaron diversas personalidades del catolicismo y de la educación de todo el país ${ }^{17}$. Además de las conferencias y talleres se realizaron homenajes al Libertador San Martín, a España por su obra evangelizadora y a la Cruz de los Milagros de Corrientes con la colocación de una placa en la columna conmemorativa ubicada en la punta Arazaty, recordando al fundador de la ciudad, a los franciscanos Rivadeneira y Alegre por sus aportes en los primeros años de vida de la cuidad, y a los correntinos que en 1713 en la Información Jurídica habían declarado los milagros de la $\mathrm{cruz}^{18}$.

\footnotetext{
${ }^{16}$ Por ejemplo se rescata la actuación de Fray Justo Santa María del Oro, algo completamente inédito en el discurso histórico de Corrientes. Senador Luis Monferrer DSCSC. 10 de julio de 1950- homenaje al 9 de julio, p. 237.

17 Estuvieron presentes el Pbro. Dr. Manuel Moledo; R. P. Victorio Bonamin, profesor en Rosario y director de la Revista Didascalia; el obispo del Chaco Mons. Nicolás de Carlo, Mons. José Alumni, el Director General de Enseñanza Religiosa de la Nación, Dr. Leonardo Benítez de Aldama; el Inspector de Enseñanza Religiosa de la Nación, Luis Tuccio; entre otros.

18 El Liberal. Corrientes, 14 de julio de 1951, p. 1.
} 
Al mismo tiempo que se buscaba identificar los postulados del catolicismo con los del peronismo, se defendía al esencialismo y se criticaba a aquellas otras corrientes filosóficas como el existencialismo de Sartre y Camus que negaban la existencia de Dios, ubicándolas como simples "modas intelectuales y doctrinas falsas de la desesperación"19.

Esta identificación entre Iglesia y peronismo se irá resquebrajando durante la segunda presidencia de Perón derivando en un abierto enfrentamiento que también se verá reflejado en el abandono del discurso de la hispanidad y su reemplazo por el de la latinidad $^{20}$. Esto también ocurrirá en la provincia de Corrientes, aunque un tanto tardíamente y sin presentar el nivel de enfrentamiento que se dio en otros lugares del país.

Según Zanatta (2009), el conflicto entre la Iglesia y el peronismo empezó a vislumbrarse a partir de la reforma constitucional de 1949 y fue acentuándose paulatinamente durante la segunda presidencia de Perón. El distanciamiento se originó a partir de la mayor injerencia que empezó a tener el estado en asuntos que la Iglesia consideraba exclusivos de su competencia y en la medida que el peronismo fue abandonando una "política religiosa" para intentar convertirse en una "religión política". Estos enfrentamientos se dieron en todo el país, sin embargo, en Corrientes nunca llegaron a plantearse de modos violentos o extremos, Iglesia y gobierno provincial siguieron manteniendo buenas y cordiales relaciones ${ }^{21}$.

\section{La cruz de los milagros y la Historia de Corrientes}

A tono con la reivindicación que hizo el peronismo del pasado hispano y de las raíces católicas de la argentinidad, en la provincia de Corrientes también se tomaron

19 El Liberal. Corrientes, 7 de septiembre de 1951, p. 2.

20 Según Rein (1991) Perón fue paulatinamente abandonando el discurso de la hispanidad reemplazándolo por el de la latinidad, especialmente desde fines de 1954, cuando se estrecharon de las relaciones argentino-italianas.

21 Son aún escasos los trabajos que analizan las relaciones entre la Iglesia y el peronismo en las provincias, mayoritariamente los estudios se centran en los sucesos ocurridos en la Capital Federal, y parten del supuesto que en el marco de su enfrentamiento con el peronismo la institución eclesiástica actuó como eje aglutinante de una oposición política debilitada y desarticulada, que encontró en el conflicto desatado a fines de 1954 una oportunidad inédita para socavar al gobierno (CAIMARI, 1995 y BIANCHI, 2001). Entre los pocos trabajos que se acercan a este tema en las provincias se destacan los aportes de César Tcach, quien subrayó el protagonismo del partido radical de Córdoba y su articulación con la Iglesia Católica en la conspiración contra el gobierno (TCACH, 2006). Más recientemente, aparecieron otros trabajos que empezaron a desentrañar este proceso en otros espacios provinciales, así por ejemplo, en el caso tucumano se plantea una situación muy similar a la correntina en la que los enfrentamientos entre la Iglesia y el gobierno nunca llegaron a plantearse en la forma virulenta que se dieron en Capital Federal o Córdoba ( LICHTMAJER y SANTOS LEPERA, 2012) 
medidas tendientes a retomar esa tradición que había sido tan cuestionada por la historiografía liberal predominante. Se buscó dotar al naciente movimiento, de una identidad y una tradición que se enlazara con la historia misma de la provincia, liberada de los modelos culturales impuestos por el liberalismo.

Uno de los acontecimientos del pasado provincial que reunía todos los elementos primordiales para ese propósito era el "milagro de la cruz", hecho que de acuerdo con la tradición había ocurrido en torno a la fundación de la ciudad en 1588. El hecho, tal como ya mencionamos, había sido objeto de varias polémicas y había tenido interpretaciones contrapuestas entre los historiadores correntinos en el pasado. Reivindicar su existencia permitía unir los dos principales legados que se buscaba rescatar del pasado argentino, -el catolicismo y la hispanidad- con el mismo origen de Corrientes.

En 1944, durante la intervención nacionalista de David Uriburu, ya se había dispuesto el cambio de nombre de la plaza ubicada frente a la Iglesia La Cruz en la ciudad de Corrientes (en la que se venera el madero que de acuerdo con la tradición fue objeto del hecho sobrenatural) que dejó de llamarse José Ramón Vidal, en honor al médico caído durante la epidemia de fiebre amarilla de fines del siglo XIX, para pasar a llamarse simplemente La Cruz.

En 1949, un tiempo antes de la asunción de Juan Filomeno Velazco como gobernador, un decreto de la intervención dispuso la publicación de un trabajo escrito por Monseñor Ángel Navea (1871- 1954), que había sido párroco de la Iglesia La Cruz, titulado La Cruz de los Milagros de Corrientes. (Evocación y acotaciones críticohistóricas). En los considerandos del decreto que disponía su publicación se argumentaba que era "el único especialmente dedicado al suceso y realizado con el más óptimo rigor lógico, ecuanimidad y un sentido de exaltación de Corrientes" desconociendo por completo que los más importantes historiadores correntinos ya habían tratado ese tema desde diversas perspectivas, no siempre aceptando la idea del milagro. El decreto establecía además que esta publicación, debía ser distribuida de manera gratuita a todos los directivos y maestros de escuela, a los alumnos de quinto y sexto grados y a las bibliotecas escolares, oficiales y populares de la provincia.

Con la edición de este trabajo, el gobierno buscaba "destacar los valores permanentes de la tradición de los pueblos" remarcando el hecho de que la fundación de Corrientes con la veneración de la Cruz de los Milagros se convertía en un blasón 
singularmente glorioso que muy pocos pueblos del mundo podían detentar pues Corrientes era el único que el 3 de mayo de cada año veía coincidir su celebración local con la Universal de la Cruz del Calvario, rescatada por hazañas del emperador Constantino $^{22}$.

El libro, que desde el punto de vista historiográfico no hacía ningún aporte novedoso al hecho en cuestión, buscaba -a través de la publicación de un cúmulo de antecedentes y referencias históricas, apelando fundamentalmente a la emotividad y con la utilización de una prosa poética- la confirmación del milagro de la cruz y la consagración de la identificación entre la raíz hispana y católica, la Cruz de Cristo y Corrientes.

"Su cruz, constituye el centro de su historia" afirma Navea en las conclusiones, agregando luego "sin desmentir su raza, ni el honor y gloria de la sangre española que corre por sus venas" (NAVEA, 1946). El propósito manifiesto del peronismo correntino de retomar las raíces hispanas y católicas aparece con claridad en esas líneas. La decisión de reeditarlo y repartir el libro gratuitamente entre alumnos, profesores, maestros y bibliotecas populares, completaba la operación historiográfica a favor de la imposición de esta tradición.

Además de la publicación de este trabajo se proyectó la erección de un importante monumento en la punta Arazaty, el lugar donde -según se había determinado- se realizó el desembarco de los fundadores de la ciudad. El proyecto, presentado por el senador peronista Luis Monferrer aunque no llegó a concretarse incluía la instalación de una biblioteca y un museo y una edificación especial que protegiera la antigua columna conmemorativa levantada por el gobernador Pedro Ferré en $1828^{23}$.

\section{Nacionalismo y Revisionismo en las lecturas peronistas del pasado de Corrientes}

Durante los años de predominio del peronismo se multiplicaron las conmemoraciones y las alusiones a hechos históricos en los discursos políticos. Historia y política se entrecruzaron y las referencias a temas y personajes históricos fueron una constante en los debates parlamentarios y en la prensa política (QUATTROCCHIWOISSON, 1998, caps. 8, 9 y 10). Aunque peronismo y revisionismo no se

22 Decreto del Interventor Federal Estanislao de la Torre del 7 de febrero de 1949. En: Diario del Foro. Corrientes, 10 de febrero de 1949.

23 El Liberal. Corrientes, 16 y 26 de julio de 1951, p. 2. 
identificaron completamente sino hasta después de la caída de Perón -cuando él mismo se proclama revisionista en Los vendepatrias (1957)- es indiscutible que esta visión alternativa del pasado argentino que provenía del nacionalismo, encontró un lugar en el imaginario histórico de un grupo activo de militantes peronistas (CATTARUZZA, 2003, pp. 161-169 y QUATTROCCHI-WOISSON, 1998, pp. 265- 281). En el caso del peronismo correntino este rasgo aparece con mayor fuerza, planteándose una más temprana identificación con el revisionismo.

Como ya destacamos, el aporte ideológico del nacionalismo fue particularmente evidente en el proceso de construcción del peronismo correntino por tratarse de una provincia que se había caracterizado -hasta entonces- por el predominio de políticas de estilo liberal-conservador, motivo por el cual constituye una puerta de entrada preferencial para el abordaje de este problema. La Alianza Libertadora Nacionalista tuvo en este proceso un papel preponderante, sus miembros, fueron al mismo tiempo importantes colaboradores del primer peronismo correntino, muchos pasaron a formar parte de sus filas y ocuparon cargos importantes durante el gobierno peronista, especialmente hasta 1953 (SOLIS CARNICER, 2010, pp. 9-38).

De acuerdo con el desarrollo que venimos haciendo, el peronismo, como movimiento que irrumpe en la política argentina a mediados del siglo XX, hizo uso del pasado y apeló a él. Desde el poder buscó reinterpretar la historia nacional y provincial a fin de legitimar su posición a través de la construcción de una tradición particular que lo identificara y al mismo tiempo, lo diferenciara de las otras fuerzas políticas precedentes. En este proceso, según vimos, se valió de los aportes del nacionalismo que desde hacía décadas venía cuestionando al liberalismo y planteando a través de los autores revisionistas versiones alternativas del pasado nacional.

Más allá de la importancia que tiene en este proceso la construcción de un discurso histórico coherente, el peronismo no tuvo en Corrientes un historiador oficial. El caso mencionado en el apartado anterior de Mons. Ángel Navea constituyó un hecho aislado y puntual de una publicación histórica escrita por un sacerdote que fue rescatada por el gobierno peronista porque reafirmaba los principios de la hispanidad católica que ellos buscaban defender pero cuyo autor no se dedicó a los estudios históricos más allá de lo ya señalado. La figura de Francisco Manzi (1883-1954) tampoco llegó a ocupar ese lugar. Se trata de un italiano nacionalizado argentino, periodista, historiador, funcionario, cronista, artista plástico y docente que fue nombrado director del Museo 
Histórico y de Bellas Artes en 1945 y delegado de la Comisión Nacional de Monumentos y Lugares Históricos y del Sindicato de Escritores Argentinos en 1951. Paralelamente, ejerció la docencia enseñando pintura e italiano. Ligado preferentemente a las letras y a las actividades artísticas, más allá de algunos escritos históricos que alcanzó a publicar -y a pesar de su cercanía con el gobierno-, tampoco llegó a convertirse en el historiador oficial del peronismo correntino ${ }^{24}$.

Sin embargo, los debates parlamentarios, las editoriales de la prensa partidaria y las publicaciones conmemorativas permiten reconstruir la posición historiográfica adoptada por el peronismo correntino pues la apelación a temas históricos en los discursos políticos se multiplicó en esos años. Este hecho se constituyó en una novedad para la política de Corrientes pues las interpretaciones centrales del pasado provincial y nacional eran, hasta ese momento, coincidentes entre los diferentes sectores políticos y no eran consideradas motivos de discusión o revisión. Con la apropiación que hicieron los diversos sectores políticos de las distintas interpretaciones y versiones del pasado provincial, éste se convirtió en un espacio más de disputa política puesto que esos pasados -y sus resignificaciones- tenían también una función de legitimación de las prácticas políticas del presente.

En esos años se multiplicaron las conferencias sobre el nacionalismo y sobre diversos temas históricos, siempre auspiciadas y fomentadas desde el estado. Una invitación a una conferencia sobre el nacionalismo dictada por Raúl Puigbó en 1949, secretario general de la Alianza Libertadora Nacionalista era titulada en un periódico oficialista que hacía su difusión como El tema del momento ${ }^{25}$. Rápidamente, el revisionismo y sus interpretaciones del pasado nacional y provincial empiezan a ser motivo de debate público. Referencias históricas y al revisionismo se repiten permanentemente en los debates legislativos tal como aparece en el discurso del diputado peronista César Espíndola Moreyra en una sesión de la cámara en 1949:

[...] En la historia [...] o se es revisionista porque amamos la verdad, o se acepta cualquier cosa en historia. [...] Personalmente, soy revisionista en historia, porque tengo mis dudas respecto a una

\footnotetext{
${ }^{24}$ Entre sus trabajos merecen citarse Impresiones de Viaje (Breves Apuntes sobre el territorio Misiones Corrientes (1910), El Dante (1912), Río de Janeiro Ciudad de Ensueño (1923), Perú y Bolivia o el Imperio del Sol (1926), Geografía de la Provincia de Corrientes (1931), Tradiciones y Leyendas Correntinas (1938), El Chaco de la Historia, de la Leyenda y la Tradición (1945), Viejo Taragüí. Crónicas Narraciones y Leyendas de la Tradición y Mitología de Corrientes (1946), El Brigadier General Don Pedro Ferré (1951), Síntesis Histórica de la Fundación de Itatí y Semblanza de su fundador Fray Luis de Bolaños (1952). (COCCO, 2009, pp. 57- 68)

25 El Diario del Foro. Corrientes, 16 de mayo de 1949, p. 5.
} 
condición fundamental que requiere el historiador para que sea tal, y para que la historia sea una lección: la imparcialidad. [...]

[...] Si la historia nos llega adulterada, si la historia nos llega escrita por los enemigos de una situación personal, de aquel instante de la vida de un pueblo. Si la historia nos llega nada más que por un solo conducto, entonces tenemos el derecho a pensar, si analizamos un poco, que nosotros estamos viendo a la historia a través de la cerradura de una llave, pero que no la conocemos integralmente [...](Dip. César Espíndola Moreyra. DSCDC. 28 de noviembre de 1949, 8 sesión extraordinaria, p. 1138).

Esta difusión del revisionismo y de nuevas perspectivas del pasado provincial y nacional generó preocupación entre aquellos sectores que por primera vez veían cuestionados los principios de la historia e identidad provincial construidos según el modelo liberal y que ya se consideraban consolidados. Esa preocupación aparece con claridad en una nota editorial publicada en 1948 en el diario La Mañana de Corrientes, representativo del sector autonomista:

Hay ciertas corrientes del pensamiento popular, [...] que si bien son irresponsables a todas luces, pueden con su actitud acrecentar prosélitos y confundir a la opinión pública para lograr sus fines, alejados de todo patriotismo y de bien general. Entre estas corrientes figura la del "revisionismo histórico" cuya finalidad es reivindicar la memoria del tirano Rosas y sostenido por personas de edad madura y secundada con audacia por jóvenes reaccionarios, [...]

La corriente enunciada tiene sus adeptos en círculos legislativos y gubernativos de algunos estados argentinos y causa estupor porque, desde las altas esferas, esos revisionistas, se nieguen al repudio de la memoria de un gobernante que ya tiene sobre su nombre el juicio adverso de la historia [...]". 'La Mañana. Corrientes, 28 de octubre de 1948. P 3.)

Si el avance y la amplia difusión del revisionismo en los diversos sectores de la política generaban preocupación entre los adversarios al peronismo, ésta se exacerbó al momento de ver como esta nueva versión del pasado empezaba a ser transmita en las escuelas y generaba una rápida adhesión entre los estudiantes ${ }^{26}$.

Al reivindicar la figura de Rosas y su época, el revisionismo venía a socavar uno de los temas centrales en torno a los cuales Corrientes había construido su identidad provincial -el de la cruzada libertadora y la lucha contra Rosas- que le había permitido ubicarse en el lugar de defensora del federalismo y de la organización nacional y en contra de la tiranía. Para cualquier correntino, reivindicar a Rosas significaba entrar en contradicción con uno de los pilares con los cuales se había construido su identidad.

26 La Razón. Mercedes (Corrientes). 11 de agosto de 1951, p 1.

Revista Eletrônica da ANPHLAC, n.14, p. 197-221, jan./jun. 2013.

http://revista.anphlac.org.br/index.php/revista 
Quizás sea por ese motivo que las discusiones en torno a esos temas en la legislatura no llegan nunca a tonos muy exacerbados, tratando de encontrar alguna posición intermedia entre ambas interpretaciones.

Más allá de reivindicar la figura de Rosas, los peronistas no se animaron nunca a votar en contra de los homenajes a las batallas de Pago Largo o Caá Guazú planteadas por sus adversarios, sin embargo, tampoco fueron ellos los movilizadores de dichos homenajes que siempre partieron del sector opositor. Los legisladores peronistas encontraron los argumentos para votar a favor de dichos homenajes pero sin alejarse de la interpretación histórica que ellos hacían de ese proceso. De ese modo, lograron construir un discurso según el cual la Batalla de Caá Guazú -o la cruzada libertadora en general- merecían ser recordadas porque simbolizaban la valentía y heroicidad de los correntinos. Es decir, era la consagración de la correntinidad, que había sido engañada por intereses externos. Estas batallas merecían ser recordadas por haber participado en ellas los más pobres de Corrientes que, a pesar de haber entregado sus vidas, no habían recibido los beneficios de la libertad ni las conquistas sociales que se merecían y que solo con el peronismo se les había empezado a reconocer ${ }^{27}$. La batalla de Caá Guazú, en particular, valía ser recordada, no por la lección histórica que ella podía brindar sino porque se trató de una batalla técnicamente completa en la que se había consagrado la correntinidad. Así por ejemplo se expresó el diputado peronista César Espíndola Moreyra, cuando se trató en el recinto de la Cámara de Diputados una propuesta de Homenaje a la Batalla de Caá Guazú plateada por el bloque radical en 1949:

[...] De manera entonces, que nosotros tenemos motivos para tener nuestras dudas con respecto a la finalidad de aquella campaña [...]. Por eso, y con estas reservas, yo adhiero al homenaje que se solicita, adhiero como correntino, porque veo en la batalla de Caá Guazú los manes de los héroes que gestaron la nacionalidad, porque veo en la batalla de Caá Guazú el espíritu y temple viril de esta Corrientes heroica [...]. Veo en la batalla de Caá Guazú, el temple viril de este Corrientes que puede reeditar esa gesta gloriosa en cualquier oportunidad, y desde ese punto de vista, como un homenaje a ese esfuerzo de sus hijos, adherimos ampliamente al homenaje que acaba de solicitarse (Dip. César Espíndola Moreira. CSCDC. 14 de noviembre de 1949, p. 1136).

Los radicales responden a los argumentos esgrimidos por el oficialismo afirmando que adherir al homenaje de la Batalla de Caá Guazú solo por su valor técnico

\footnotetext{
${ }^{27}$ Conv Sabino Acosta Monzón en la Convención Constituyente 1949. 30 de mayo de 1949, cont. de la 3era sesión ordinaria, pp. 169- 170.
} 
era quitarle toda su riqueza, porque ésta era la culminación y la reedición del hecho histórico de Pago Largo. Similares razones se esgrimieron en otra discusión cuando se planteó la posibilidad de aprobar un subsidio para levantar un monumento al General Paz y a la Batalla de Caá Guazú. No se opusieron a ello los senadores peronistas pero como contrapartida, solicitaron se levante también un monumento a Pedro Ferré a quien definieron como "el defensor, sostenedor y el campeón del auténtico federalismo y uno de los próceres de más límpida trayectoria en la historia de la nación” ${ }^{28}$. Además, consiguieron que en la placa en la que se recordaba la Batalla se inscribiera la leyenda "A los vencedores y vencidos" argumentando que la misma había sido sobre todo una lucha entre argentinos y que por lo tanto se debían recordar y homenajear a todos sus protagonistas, fueran del bando que fuesen ${ }^{29}$.

Según la reinterpretación de la historia argentina que plantea el peronismo, el país había vivido un largo paréntesis a partir de la Batalla de Caseros -que había provocado la caída de Rosas- hasta el 4 de junio de 1943, momento en el que planteaban se habían retomado los ideales perdidos y abandonados por todos aquellos quienes habían gobernado al país desde la sanción de la Constitución. Sólo Perón había logrado retornar a las verdaderas raíces de la cultura argentina y al verdadero modelo sanmartianano:

Desde Caseros, es decir desde el 3 de febrero de 1852 hasta el 4 de junio de 1943, [...] el país ha sufrido, en mi concepto, un grave y trágico paréntesis, [...] se había estructurado el país sobre normas completamente ajenas a las verdadera idiosincrasia y al verdadero carácter de los argentinos que no eran otras que las virtudes raciales heredadas de la Madre Patria, [...] Llegamos a una conclusión de que cuando el pueblo sintió que había alguien detrás de él que lo respaldaba [...] surgió como un solo hombre y se cuadró el 17 de octubre y se cuadró el 24 de febrero para reencontrarse a sí mismo y decirle al mundo que ahí había un retoño de España que estaba fructificando, tal cual lo había querido y soñado alguna vez el general San Martín.[...]" (César Espíndola Moreyra. Sesión Homenaje a San Martín 29 de diciembre de 1950. Asamblea Legislativa. P 896- 897)

\footnotetext{
28 Pedro Ferré, defensor del federalismo y gobernador de Corrientes en cuatro oportunidades (18241828 ; $1830-1833$; 1839-1839 y 1839-1842) era rescatado por la historiografía revisionista (lo había sido por Justo Díaz de Vivar, por ejemplo) por sus actuaciones durante las gestiones del pacto federal, previas al enfrentamiento de la provincia con Rosas. Es exhibido por esta corriente como el único que entendió que la política de Rosas consistía en mantener la hegemonía de Buenos Aires con cierto respeto de la autonomía de las provincias, que el poder de Rosas era inconmovible y que inevitablemente chocaría con él al pretender salvar el derecho a la autonomía de su provincia pero sin embargo, mantuvo su posición doctrinaria. Posteriormente consideraban que se equivocó al continuar la lucha contra Rosas inaugurada por Berón de Astrada.

${ }_{29}$ DSCSC. 31 de julio de 1946, pp. 400- 407.
}

Revista Eletrônica da ANPHLAC, n.14, p. 197-221, jan./jun. 2013.

http://revista.anphlac.org.br/index.php/revista 
Además de la época de Rosas, la reconquista de Buenos Aires luego de las invasiones inglesas, fue otro de los acontecimientos del pasado nacional reivindicados por el peronismo ${ }^{30}$. En este caso -como en muchos otros- los peronistas intentan realizar un paralelismo con su situación presente, resignificando la masiva movilización popular a favor de Perón realizada el 17 de octubre de 1945 "como la nueva reconquista del pueblo argentino" ${ }^{31}$. En la construcción de nuevos sentidos de los hechos y acontecimientos históricos que llevó adelante el peronismo, el 17 de octubre, se convirtió en una fecha central de la historia del nuevo país que el peronismo se había propuesto fundar. De acuerdo a la interpretación que construyeron, a partir de ese momento el pueblo había retomado el impulso de su verdadera soberanía. A su vez, ese pronunciamiento era comparable solo con aquel otro pronunciamiento popular ocurrido en 1810 cuando el pueblo se amotinó en la plaza y solicitó al Cabildo de Buenos Aires conocer lo que estaba pasando.

Además de la resignificación de los hechos del pasado nacional, paulatinamente irá creciendo entre los peronistas un culto a sus líderes, fundamentalmente a las personas de Juan Domingo Perón y su esposa, Eva Duarte de Perón. Esto llevará a reemplazar nombres de calles, de rutas, de paseos, etc. que serán rebautizados con el nombre de los líderes del movimiento. Una de estas medidas, que causó una fuerte disconformidad por parte de la oposición correntina fue la aprobación de una ley por la cual se cambió el nombre al departamento de Monte Caseros por el de Eva Perón. Los radicales se opusieron al proyecto argumentando que el nombre de Monte Caseros era representativo de un momento histórico fundamental para la historia institucional del país -el de la batalla de Caseros- motivo por el cual el gobernador Pujol había decidido,

\footnotetext{
30 En 1806 y 1807 se produjeron en Buenos Aires dos expediciones militares de la corona británica contra el Virreinato del Río de la Plata. Ambos intentos fracasaron. En la primera invasión, de 1806, las tropas británicas ocuparon la ciudad de Buenos Aires -capital del Virreinato- y fueron vencidas 45 días después por un ejército proveniente de Montevideo comandado por Santiago de Liniers al que se sumaron milicias populares porteñas, proceso conocido posteriormente como La Reconquista. La segunda invasión se produjo en 1807, en esa oportunidad las tropas británicas luego de tomar Montevideo fueron rechazadas al intentar ocupar Buenos Aires por las fuerzas defensoras que se componían de tropas regulares y de milicias urbanas, integradas por población que se había armado y organizado militarmente; este proceso es conocido como la Defensa. La participación de las milicias en la Reconquista primero y en la Defensa, después, aumentaron el poder y la popularidad de los líderes criollos militares e incrementaron la influencia y el fervor de los grupos independentistas. Tanto la Reconquista como la Defensa de Buenos Aires ante las Invasiones Inglesas tuvieron un lugar relevante como antecedente inmediato de la Revolución de mayo de 1810 que dio inicio al proceso de Independencia en el Río de la Plata.

31 Diputado Fernando Bucarón DSCDC, 8 de agosto de 1949, p. 363.
} 
en el pasado, cambiar el nombre original de dicho pueblo que antes se llamaba Paso de los higos ${ }^{32}$.

Hacia 1950 se plantea el cambio de nombre a las dos rutas provinciales más importantes. La que recorría la costa del río Uruguay pasaría a llamarse José de San Martín, mientras que Juan Domingo Perón se llamaría la que recorría la costa del Paraná. El proyecto, que también fue muy discutido por la bancada opositora, buscaba una vez más entrelazar el pasado con el presente y colocar en un pie de igualdad a las figuras de San Martín y Perón. En la fundamentación que hicieron los legisladores peronistas dejaron bien claro este propósito:

[...] nos guía un estricto espíritu de justicia histórica. Nosotros queremos desde ya, ir haciendo la historia futura del país y de esta hora que vive el país; y es por eso que vamos amojonando el camino y que vamos colocando las piedras fundamentales de la futura historia del país, para que no ocurra, y para que no se reedite, [...] la falsificación histórica que por tanto tiempo ha perturbado nuestros espíritus, haciéndonos aplaudir gestos y actitudes de hombres que en el pasado no fueron precisamente los que trabajaron para honrar a la Nación (Dip. César Espíndola Moreyra. DSCDC. 27 de septiembre de 1950, p. 437).

El peronismo irá, entonces, no solo planteando una versión alternativa de la historia argentina y provincial diferente a la construida por la historiografía liberal sino que, a su vez, les dará un nuevo significado. Primero, buscará filiar al peronismo con una vertiente de la historia argentina alejada del modelo oligárquico liberal de fines del siglo XIX, cercana a las raíces hispanas y católicas de la cultura argentina. Luego, intentará identificar hechos del pasado con acontecimientos del presente, operación llevada a cabo con la revolución del 4 de junio primero y el 17 de octubre, después. Ambos acontecimientos serán interpretados por el peronismo como la reedición de los ideales de la revolución de mayo. Finalmente, y en particular a partir de las ceremonias llevadas a cabo con motivo de conmemorarse el centenario de la muerte de San Martín en 1950, se buscará alcanzar la plena identificación entre San Martín y Perón ${ }^{33}$.

\section{Reflexiones finales}

32 Senador Porfirio Aquino DSCSC. 26 de agosto de 1952, p. 300.

33 Esta nueva disputa histórico-política también se verá reflejada en el seno de la filial local del Instituto Sanmartiniano que en 1950 atravesó una fuerte crisis interna entre sus miembros peronistas y antiperonistas por el uso político que se hizo de la figura de San Martín. 
La irrupción del peronismo trajo consigo novedades importantes tanto en las formas de hacer política como en los modos de interpretar el pasado de Corrientes. Desde el poder, y buscando imbricar el pasado con el presente, se preocupó de otorgar nuevos significados a las historias de la nación y de la provincia con el fin de legitimar su posición a través de la construcción de una tradición particular que lo identificara y al mismo tiempo, lo diferenciara de las otras fuerzas políticas precedentes.

Los dirigentes del peronismo provincial y especialmente sus representantes en la legislatura, a través de una clara operación histórica y política irán elaborando un discurso histórico alternativo al liberal en el que los aportes del nacionalismo y del revisionismo resultan evidentes. Por otro parte, se observa un abandono del discurso exacerbado de la correntinidad -propio de los historiadores y los intelectuales de la primera mitad del siglo $\mathrm{XX}$-, en el que se destacaba la situación de Corrientes como provincia postergada dentro de la nación y en la que se planteaba una permanente confrontación entre los lugares que ocupaban la nación y la provincia. Con el peronismo, en cambio, al tratarse de un movimiento nacional con un liderazgo fuerte y centralizador como el ejercido por Perón, ese discurso se diluye y la provincia pasa a fundirse con la nación. La argentinidad reemplaza a la correntinidad y en ese proceso fueron necesarias las búsquedas de nuevos símbolos con los cuales identificarse y en donde sostenerse.

El rescate de la cruz de los milagros dentro del pasado colonial de Corrientes permitió hilvanar la tradición nacional propuesta por el peronismo -que reivindicaba las raíces católicas e hispánicas de la argentinidad- con la propia historia de Corrientes y permitió darle a los peronistas correntinos una tradición alternativa y diferente a la liberal construida por los historiadores e intelectuales correntinos desde fines del siglo XIX.

Por otra parte, la versión revisionista de la historia con la recuperación de la figura de Rosas y de su época les permitirá apartarse del discurso tradicional de los políticos correntinos que justamente basaban sus argumentos reivindicatorios en la búsqueda de reconocimiento nacional por todos los esfuerzos realizados por Corrientes en la lucha contra Rosas y a favor de la organización nacional. Alejarse de este discurso, aunque sin enfrentarlo del todo - pues la misma identidad correntina se había construido en torno a esos tópicos- les permitió plantear pasados alternativos y la posibilidad de rescatar a otros héroes. El silencio en torno a Berón de Astrada o sobre la Batalla de 
Pago Largo, tan largamente reivindicados en el pasado, es un hecho significativo y absolutamente novedoso para Corrientes.

Para finalizar, creemos importante señalar que, aunque las voces opositoras y el discurso histórico tradicional se vieron acallados durante los años de predominio del peronismo, retornarán con fuerza después de la caída de Perón, en 1955. Sin embargo, el análisis y la evaluación de ese proceso escapan a los objetivos que nos habíamos propuesto en este artículo.

\section{Referencias bibliográficas:}

BIANCHI, Susana. El integrismo católico en los fundamentos de la Enseñanza religiosa. En: Catolicismo y peronismo. Religión y Política en la Argentina 1943- 1955. Instituto de Estudios Histórico-Sociales "Prof. Juan Carlos Grosso", Tandil, 2001, pp. 319- 326.

BOTANA, Natalio. El orden conservador. La política argentina entre 1880 y 1916. Buenos Aires: 5ta ed, Sudamericana, 1998

CAIMARI, Lila. Perón y la Iglesia católica. Religión, Estado y sociedad en la Argentina 1943-1955. Buenos Aires: Ariel, 1995.

CATTARUZZA, Alejandro. El revisionismo: Itinerarios de cuatro décadas. En: CATTARUZZA, Alejandro y EUJANIÁN, Alejandro. Políticas de la Historia. Argentina 1860- 1960. Buenos Aires-Madrid: Alianza Editorial, 2003.

CORNBLIT, Oscar. La Opción Conservadora en la Política Argentina. En: Desarrollo Económico, $\mathrm{n}^{\circ} 14$, enero- marzo. 1975.

CHAMOSA, Oscar. Criollo and Peronist: The Argentine Folklore Movement during the First Peronism, 1943- 1955. En: CHAMOSA, Oscar y MATTHEW, Karush. The New Cultural History of Peronism: Power and Identity in Mid- Twentieth-Century Argentina. Durham: Duke Uniersity Press, 2010.

COCCO, Dina. Prof. Francisco Manzi. Escritor, periodista y director del Museo Histórico. En: La verdad sin rodeos. Revista Anual del Instituto de Investigaciones Históricas de Corrientes, $\mathrm{n}^{\circ}$ 4, Corrientes, Moglia ediciones, 2009, pp. 57- 68

DEVOTO, Fernando y PAGANO, Nora. Historia de la Historiografía Argentina. Buenos Aires, Sudamericana, 2009. 
LEONI, María Silvia. La Historiografía correntina en la primera mitad del siglo XX: En: MAEDER, Ernesto y otros. Visiones del pasado. Estudios de Historiografía de Corrientes. Corrientes, Moglia ediciones, 2004, pp. 15- 41.

La Historiografías provinciales Chaco y Corrientes. De los inicios a la profesionalización del campo historiográfico. Nordeste Segunda época, Serie: Docencia No 18 Historia. Facultad de Humanidades, Universidad Nacional del Nordeste, 2003.

LICHTMAJER, Leandro y SANTOS LEPERA, Lucía. Repensando el golpe de 1955 desde una perspectiva provincial: Iglesia católica y radicalismo en Tucumán. En: Tercer Congreso de Estudios sobre el peronismo. Jujuy, Red de Estudios del PeronismoUniversidad Nacional de Jujuy. Versión en CD Rom, 2012.

MACOR, Darío. Las tradiciones políticas en los orígenes del peronismo santafesino. En: MACOR, Darío y TCACH, César (ed). La invención del peronismo en el interior del país. Santa Fe: Universidad Nacional del Litoral, 2003.

MAEDER, Ernesto. La historiografía correntina. Algunas observaciones sobre su visión de la época colonial en esa provincia. En: MAEDER, Ernesto y otros. Visiones del pasado. Estudios de Historiografía de Corrientes. Corrientes: Moglia ediciones, 2004, pp. $171-188$.

MALAMUD, Carlos. Liberales y conservadores: los partidos políticos argentinos (1880-1916). En: Estudios Interdisciplinarios de América Latina y el Caribe. Vol. 8, $\mathrm{n}^{\circ}$ 1. 1996-1997. Facultad de Humanidades Lester y Sally Entin. Escuela de Historia. Instituto de Historia y Cultura de América Latina. Universidad de Tel Aviv.

MANTILlA, Manuel Florencio. Crónica Histórica de la provincia de Corrientes, Buenos Aires: 1972. Tomo I. (1era ed., 1928).

NAVEA, Angel. La cruz de los milagros de Corrientes. (Evocación y acotaciones crítico-Históricas), 1946.

PASAMAR ALZURIA, Gonzalo. Los historiadores y el "uso público de la historia": viejo problema y desafío reciente. En: Ayer, Revista de la Asociación de Historia Contemporánea, no 49, 2003, pp. 221- 248.

PUIGGRÓS, Adriana (dir). Historia de la educación argentina. Tomo 5. Peronismo: cultura política y educación (1945-1955). Buenos Aires: Galerna, 2006.

QUATTROCCHI- WOISSON, Diana. Los males de la memoria. Historia y política en la Argentina. Buenos Aires: Emecé editores, 1998. 
QUIÑONEZ, María Gabriela. Entre el pasado y el presente: Historia y política en Corrientes en torno de la lucha contra la "Tiranía Rosista" (1839-1941). En: Revista de Historia de América, $\mathrm{n}^{\circ}$ 126, enero- junio de 2000. Instituto Panamericano de Geografía e Historia, pp. 19- 52. . Un defensor de Rosas entre los historiadores correntinos: Justo Díaz de Vivar, entre la tradición local y el revisionismo de los años treinta En: XXIV Encuentro de Geohistoria Regional Resistencia, 2004 IIGHI-Conicet, pp. 472- 479.

REIN, Raanan. Hispanidad y oportunismo político: el caso peronista. En: EIAL, Universidad de Tel Aviv, Vol 2, nº 2, julio-diciembre, 1991.

SOLIS CARNICER, María del Mar. La Alianza Libertadora Nacionalista y los orígenes del peronismo. Una aproximación desde la provincia de Corrientes (19441947). En: Revista Historia de América del Instituto Panamericano de Geografía e Historia ${ }^{\circ}$ 141, México, 2010, pp. 9- 38.

TCACH, César. Sabattinismo y Peronismo. Partidos políticos en Córdoba (1943-1955). Buenos Aires: Biblos, 2006.

ZANATTA, Loris. Breve Historia del Peronismo Clásico. Buenos Aires: Sudamericana, 2009.

\section{Fuentes Éditas}

Corrientes. Convención Constituyente. Diario de Sesiones, 1949.

Corrientes. Cámara de Diputados. Diario de Sesiones (1946- 1955)

Corrientes. Cámara de Senadores. Diario de Sesiones (1946- 1955)

\section{Publicaciones Periódicas}

La Mañana. Corrientes (1945- 1948).

El Liberal. Corrientes (1951)

Diario del Foro Corrientes (1949)

La Razón Mercedes (Corrientes) 1951.

Recebido em: agosto de 2012 e aprovado em: novembro de 2012. 